Tropical Journal of Pharmaceutical Research June 2012; 11 (3): 461-467

(C) Pharmacotherapy Group, Faculty of Pharmacy, University of Benin

Benin City, 300001 Nigeria.

All rights reserved.

\title{
GC-MS Analysis of Insecticidal Essential Oil of Aerial Parts of Paederia scandens (Lour) Merrill (Rubiaceae)
}

\author{
Kai Yang ${ }^{1}$, Qi Zhi Liu ${ }^{1}$, Zhi Long Liu ${ }^{1 *}$, Shu Shan $\mathrm{Du}^{2}$ \\ ${ }^{1}$ Department of Entomology, China Agricultural University, 2 Yuanmingyuan West Road, Haidian District, Beijing \\ 100193, ${ }^{2}$ State Key Laboratory of Earth Surface Processes and Resource Ecology, Beijing Normal University, Beijing \\ 100875, China
}

\begin{abstract}
Purpose: To investigate the chemical composition and insecticidal activity of the essential oil of the aerial parts of Paederia scandens against the maize weevil, Sitophilus zeamais.

Methods: Steam distillation of the aerial parts of P. scandens was carried out using Clavenger apparatus in order to obtain the volatile oils. Gas chromatography/mass spectrometric (GC/MS) analyses (HP-5MS column) of the essential oil were performed and its composition determined. Insecticidal activity of the essential oil was measured following topical application and seal-spaced fumigation.

Results: The main components of the essential oil were $\beta$-pinene (24.77\%), $\alpha$-pinene (8.22 \%), 1, 8cineol (8.01\%), $\delta$-terpinene (5.32\%), (E)- $\beta$-ocimene (5.21\%), linalool (4.92\%) and 4-terpineol (3.63 $\%$ ). The essential oil exhibited strong fumigant toxicity against adult $S$. zeamais with $L C_{50}$ (lethal concentration at $50 \%$ ) value of $7.14 \mathrm{mg} / \mathrm{L}$ air. P. scandens essential oil also possessed contact toxicity against S. zeamais with $L D_{50}$ (lethal dosage at $50 \%$ ) value of $47.78 \mu \mathrm{g} / \mathrm{adult}$ insect.

Conclusion: The study indicates that the essential oil of $P$. scandens has a potential for development into a natural fumigant for control of insects in stored grains.
\end{abstract}

Keywords: Paederia scandens; Sitophilus zeamais; Essential oil, Contact toxicity, Fumigant. 


\section{INTRODUCTION}

Control of insects in stored grains is based on the application of synthetic insecticides/ fumigants. However, repeated use of those fumigants for decades has led to resurgence of stored-product insect pests, sometimes resulting in the development of resistance, and had undesirable effects on non-target organisms. These problems have highlighted the need to search for new types of selective insect-control alternatives with fumigant action.

Plant essential oils and their components have been shown to possess potential for development into new fumigants and may have an advantage over conventional fumigants in terms of low mammalian toxicity, rapid degradation and local availability [1]. During the screening program for new agrochemicals from Chinese medicinal herbs and wild plants, the essential oil of the aerial parts of Paederia scandens (Lour.) Merrill (Family: Rubiaceae) was found to possess strong insecticidal toxicity against the maize weevil, Sitophilus zeamais (Motschulsky).

$P$. scandens is a climbing plant and widely distributed in China, India, Vietnam, Indonesia, Malaysia, Japan, North Korea, the Philippines and North America. In China, it is mainly distributed in Central China (Yangtze River basin and its southern region) [2]. However, it has spread quickly and recently was found in the Beijing area [3]. It is prescribed as a folk medicine for toothache, chest pain, piles, inflammation of the spleen, rheumatic arthritis and bacillary dysentery, and as also as a diuretic and emetic [4].

Previous phytochemical studies on $P$. scandens resulted in the identification of a number of anthraquinones, flavoids, terpenoids, steroids, iridoids and sulfurcontaining iridoid glucosides [5-10]. The chemical composition of $P$. scandens essential oil was also studied previously [1113]. The ethanol extract of $P$. scandens was demonstrated to possess antifeedant activity against aphids (Myzus persicae and Lipaphis erysimi) [14]. However, to the best of our knowledge, there are no reports on the activity of $P$. scandens essential oil against insect infestation in stored grains. Therefore, the objective of this study was to determine the chemical composition and toxicity of the essential oil of $P$. scandens against insects in stored grains.

\section{EXPERIMENTAL}

\section{Plant collection and identification}

Ten kilograms of the fresh aerial parts of $P$. scandens were harvested in August 2010 from Baiwangshan National Forest Park, Haidian (Beijing, China). The species was identified by $\mathrm{Dr}$ QR Liu (College of Life Sciences, Beijing Normal University, Beijing 100875) and voucher specimens (no. BNULiuzhilong-Vit-10-211) were deposited at the Herbariumof (BNU) of College of Life Sciences, Beijing Normal University.

\section{Extraction and isolation of essential oil}

The aerial parts were air-dried and first ground to powder using a grinding mill (Retsch Muhle, Germany). The powder was hydro-distilled for $6 \mathrm{~h}$ in a Clavenger apparatus. The oil was dried over anhydrous $\mathrm{Na}_{2} \mathrm{SO}_{4}$ and kept in a refrigerator $\left(4{ }^{\circ} \mathrm{C}\right)$ pending subsequent experiments.

\section{Analysis of essential oil}

Capillary gas chromatography was performed using Hewlett-Packard 5890 gas chromatograph equipped with a flame ionization detector; fused silica capillary column HP-5 (5 \% diphenyl and $95 \%$ dimethylpolysyloxane, $30 \mathrm{~m} \times 0.25 \mathrm{~mm}, 0.25$ $\mu \mathrm{m}$ film thickness); helium as carrier gas at a flow rate of $1 \mathrm{~mL} \cdot \mathrm{min}^{-1}$; and programmed temperature from 60 to $280{ }^{\circ} \mathrm{C}$ (at a rate of 2 ${ }^{\circ} \mathrm{C} . \mathrm{min}^{-1}$ ); injector temperature $270{ }^{\circ} \mathrm{C}$ and detector temperature $300{ }^{\circ} \mathrm{C}$. The components of the essential oil were separated and identified by gas 
chromatography-mass spectrometry (GCMS) using Agilent 6890N gas chromatography coupled to Agilent 5973N mass selective detector. The system was equipped with a flame ionization detector and capillary column with HP-5MS $(30 \mathrm{~m} \times 0.25$ $\mathrm{mm} \times 0.25 \mu \mathrm{m})$. GC settings were as follows: the initial oven temperature was held at $60^{\circ} \mathrm{C}$ for $1 \mathrm{~min}$ and ramped at $10{ }^{\circ} \mathrm{C} \cdot \mathrm{min}^{-1}$ to 180 ${ }^{\circ} \mathrm{C}$ where it was held for $1 \mathrm{~min}$, and then ramped at $20{ }^{\circ} \mathrm{C} \cdot \mathrm{min}^{-1}$ to $280{ }^{\circ} \mathrm{C}$ and held there for $15 \mathrm{~min}$. The injector temperature was maintained at $270^{\circ} \mathrm{C}$. The samples (1 $\mu \mathrm{L})$ were injected neat, with a split ratio of 1 : 10 . The carrier gas was helium at a flow rate of $1.0 \mathrm{ml} \cdot \mathrm{min}^{-1}$. Spectra were obtained over the scan range 20 to $550 \mathrm{~m} / \mathrm{z}$ at 2 scans s${ }^{-1}$. Most constituents were identified by gas chromatography by comparison of their retention indices with those published in the literature [11-13] or with those of authentic compounds available in our laboratories. The retention indices were determined in relation to a homologous series of $n$-alkanes $\left(\mathrm{C}_{8}-\mathrm{C}_{24}\right)$ under the same operating conditions. Further identification was made by comparison of their mass spectra with those stored in NIST 05 and Wiley 275 libraries or with mass spectra from literature [15]. Relative percentages of the oil components were calculated based on GC peak areas without using correction factors.

\section{Insects}

S. zeamais was obtained from laboratory cultures maintained for the last 10 years in the dark in incubators at $27-29^{\circ} \mathrm{C}$ and $70-$ $80 \%$ relative humidity. Adult $S$. zeamais insects were reared on whole wheat at 12 $13 \%$ moisture content. Unsexed adults of the insects used in all the experiments were about 2 weeks old.

\section{Fumigant toxicity test}

A Whatman filter paper (diameter $2.0 \mathrm{~cm}$, Cat no. 1001020) was placed on the underside of the screw cap of a glass vial (diameter 2.5 $\mathrm{cm}$, height $5.5 \mathrm{~cm}$, volume $24 \mathrm{~mL}$ ). Rangefinding studies were run to determine the appropriate testing concentrations. Ten microliters of essential oil solution was added to the filter paper. The solvent was allowed to evaporate for $15 \mathrm{~s}$ before the cap was placed tightly on the glass vial (containing 10 unsexed insects) to form a sealed chamber. Fluon (ICl America Inc) was used inside the glass vial to prevent insects from the treated filter paper. $n$-Hexane was used as controls and six replicates were used in all treatments and controls. They were incubated at $27-29$ ${ }^{\circ} \mathrm{C}$ and $70-80 \%$ relative humidity for $24 \mathrm{~h}$ and mortality of insects was observed.

\section{Contact toxicity test using topical application}

The contact toxicity of essential oil against adult $S$. zeamais was measured as described by Liu and Ho [19]. Range-finding studies were run to determine the appropriate testing concentrations. A serial dilution of the essential oil was prepared in $n$-hexane. Aliquots of $0.5 \mu \mathrm{l}$ of the dilutions were applied topically to the dorsal thorax of the insects. Controls were determined using $n$-hexane. Six replicates were used in all treatments and controls. Both treated and control insects were then transferred to glass vials (10 insects/vial) with culture media and kept in incubators. Mortality of insects was observed after $24 \mathrm{~h}$.

\section{Statistical analysis}

The results from all replicates in fumigant and contact toxicity bioassays were subjected to Probit analysis [16] using PriProbit Program V1.6.3 to determine $L_{50}$ and $L_{50}$ values, respectively [17]. Samples for which the $95 \%$ fiducial limits did not overlap were considered to be significantly different.

\section{RESULTS}

The 3-hour steam distillation of aerial parts of $P$. scandens afforded essential oil (yellow) with a yield of $0.02 \%(\mathrm{v} / \mathrm{w})$ and the density of the concentrated essential oil was determined to be $0.831 \mathrm{~g} / \mathrm{mL}$. The GC-MS analysis of the essential oil of the aerial parts 
of $P$. scandens led to the identification and quantification of 45 major components accounting for $90.05 \%$ of the total components present (Table 1). $\beta$-Pinene (24.77\%), a-pinene (8.22 \%), 1,8-cineol
$(8.01 \%)$, $\delta$-terpinene $(5.32 \%)$, and $(E)-\beta$ ocimene $(5.21 \%)$ were the main components of the essential oil; also present were linalool (4.92\%) and 4-terpineol (3.63\%).

Table 1(a): Chemical composition of the essential oil of Paederia scandens aerial parts

\begin{tabular}{|c|c|c|}
\hline Compound & $\mathbf{R I}^{*}$ & Content (\%) \\
\hline Bornylene & 907 & 0.27 \\
\hline a-Pinene & 939 & 8.22 \\
\hline Dimethyl trisulfide & 972 & 1.81 \\
\hline$\beta$-Pinene & 981 & 24.77 \\
\hline Limonene & 1030 & 1.10 \\
\hline 1,8-Cineol & 1036 & 1.94 \\
\hline$\beta$-Terpinene & 1044 & 8.01 \\
\hline 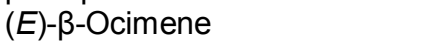 & 1054 & 5.21 \\
\hline y-Terpinene & 1057 & 2.63 \\
\hline Linalool oxide & 1076 & 1.13 \\
\hline$\delta$-Terpinene & 1090 & 5.32 \\
\hline Linalool & 1094 & 4.92 \\
\hline Phenylethyl alcohol & 1121 & 0.70 \\
\hline cis-o-Menth-2-en-1-ol & 1126 & 0.34 \\
\hline Borneol & 1167 & 1.75 \\
\hline 4-Terpineol & 1175 & 3.63 \\
\hline$\rho$-Cymene-8-ol & 1182 & 0.56 \\
\hline$\alpha$-Terpineol & 1189 & 1.32 \\
\hline Nerol & 1226 & 0.57 \\
\hline cis-Citral & 1240 & 0.36 \\
\hline 4-Acetyl-3-methylphenol & 1254 & 0.89 \\
\hline 4-Vinylguaiacol & 1311 & 1.01 \\
\hline Citronellyl acetate & 1355 & 2.10 \\
\hline Chavibetol & 1362 & 0.71 \\
\hline 2,4,5-Trimethyl benzaldehyde & 1364 & 1.95 \\
\hline$\vec{\alpha}$-Copaene & 1377 & 0.10 \\
\hline$\beta$-Geranyl acetate & 1394 & 0.47 \\
\hline trans- $\beta$-Damascenone & 1382 & 0.72 \\
\hline Methyl eugenol & 1410 & 0.46 \\
\hline Caryophyllene & 1420 & 0.54 \\
\hline (Z)- $\beta$-Farnesene & 1438 & 0.19 \\
\hline Geranyl acetone & 1453 & 0.17 \\
\hline$\beta$-Selinene & 1475 & 2.79 \\
\hline Methyl isoeugenol & 1500 & 0.30 \\
\hline$\alpha-F a r n e s e n e$ & 1505 & 0.31 \\
\hline cis-Muurola-4(14),5-diene & 1510 & 0.10 \\
\hline y-Cadinene & 1513 & 0.16 \\
\hline$\delta$-Cadinene & 1523 & 0.27 \\
\hline Dihydroactindiolide & 1531 & 0.09 \\
\hline a-Calacorene & 1543 & 0.17 \\
\hline trans-Nerolidol & 1563 & 0.28 \\
\hline Spathulenol & 1578 & 0.31 \\
\hline Caryophyllene oxide & 1581 & 0.23 \\
\hline Isoelemicin & 1596 & 0.61 \\
\hline$\alpha$-Cadinol & 1653 & 0.56 \\
\hline Total identified & & 90.05 \\
\hline
\end{tabular}

$R I=$ retention index 
Table 2: Toxicity of Paederia scandens essential oil against adult Sitophilus zeamais

\begin{tabular}{|c|c|c|c|c|c|c|}
\hline \multirow[t]{2}{*}{ Treatment } & \multicolumn{3}{|c|}{ Contact toxicity } & \multicolumn{3}{|c|}{ Fumigant toxicity } \\
\hline & $\begin{array}{c}\mathrm{LD}_{50} \\
\text { ( } \mu \mathrm{g} / \text { adult }) \\
(95 \% \mathrm{FL})\end{array}$ & $\begin{array}{l}\text { Slope } \pm \\
\text { SE }\end{array}$ & $\begin{array}{c}\text { Chi } \\
\text { square } \\
\left(x^{2}\right)\end{array}$ & $\begin{array}{c}\mathrm{LC}_{50}(\mathrm{mg} / \mathrm{L} \text { air }) \\
(95 \% \mathrm{FL})\end{array}$ & Slope \pm SE & $\begin{array}{c}\text { Chi } \\
\text { square } \\
\left(x^{2}\right)\end{array}$ \\
\hline \multicolumn{7}{|l|}{ P. scandens } \\
\hline $\begin{array}{l}\text { Mean } \\
\text { Range }\end{array}$ & $\begin{array}{c}47.78 \\
(43.53-51.91)\end{array}$ & $\begin{array}{c}3.95 \pm \\
0.37\end{array}$ & 30.63 & $\begin{array}{c}7.14 \\
(6.24-8.06)\end{array}$ & $2.17 \pm 0.28$ & 17.65 \\
\hline Pyrethrum extract & & & & - & - & - \\
\hline $\begin{array}{l}\text { Mean } \\
\text { Range }\end{array}$ & $\begin{array}{c}4.29^{*} \\
(386-470)\end{array}$ & $\begin{array}{l}0.72 \pm \\
0.01\end{array}$ & 13.51 & & & \\
\hline $\mathrm{MeBr} r^{* * *}$ & $\begin{array}{c}- \\
-\end{array}$ & - & - & $0.67^{* *}$ & - & - \\
\hline
\end{tabular}

The essential oil exhibited contact toxicity against $S$. zeamais with an $\mathrm{LD}_{50}$ value of $47.78 \mu \mathrm{g} /$ adult insect (Table 2). The essential oil also possessed strong fumigant activity against $S$. zeamais with an $\mathrm{LC}_{50}$ value of 7.14 $\mathrm{mg} / \mathrm{L}$ air (Table 2).

\section{DISCUSSION}

The main constituents of the essential oil were $\beta$-pinene $(24.77 \%)$, a-pinene $(8.22 \%)$, 1,8-cineol (8.01\%), $\delta$-terpinene (5.32\%), and $(E)$ - $\beta$-ocimene $(5.21 \%)$. The composition is different from that reported in previous studies. For example, the essential oil of $P$. scandens collected from Shanxi Province (northwestern area of China) contains isoamyl acetate $(20.2 \%)$, benzyl acetate (8.0 $\%)$, palmitic acid $(6.8 \%)$ and isoamyl caprate $(5.7 \%)$ [11]. However, the main components of the essential oil of $P$. scandens harvested from Hubei province in central China are acetic acid (31.1\%), trans-linalool oxide (10.4 $\%)$, linalool oxide $(8.5 \%)$, furfural $(7.5 \%), \beta-$ fenchyl alcohol $(7.3 \%)$, isoborneol $(6.4 \%)$ and 3-furan methanol (6.1\%) [12] while the essential oil of the plant harvested from Secontaining areas contains $\beta$-propiolactone $(7.6 \%)$, novalgin (7.0 \%), acetylmethylcarbinol (6.7\%), 3-buten-2-one $(5.4 \%)$ and dimethyl sulfone $(5.0 \%)$ [13]. Thus, there would appear to be considerable seasonal and geographic variations in the chemical composition of the essential oil of $P$. scandens because it has been proved that there is variation in the chemical composition of the essential oil of $P$. scandens collected in different areas, different plant parts and varying degree of maturity of the plant at harvest [11-13].

The essential oil of $P$. scandens exhibited contact toxicity against $S$. zeamais. However compared with the positive control (Pyrethrum extract, $25 \%$ pyrethrine I and pyrethrine II), the essential oil possesses weak acute toxicity against the weevil since the $\mathrm{LD}_{50}$ value was $4.3 \mu \mathrm{g} /$ insect in a previous report [18]. The essential oil of $P$. scandens aerial parts also possessed strong fumigant activity against $S$. zeamais insect. The commercial grain fumigant, methyl bromide (MeBr) was reported to possess fumigant activity against $S$. zeamais adults with an $\mathrm{LC}_{50}$ value of $0.67 \mathrm{mg} / \mathrm{L}$ air [19]. The essential oil of $P$. scandens is 11 times less toxic to the maize weevil compared with $\mathrm{MeBr}$.

However, the essential oil of $P$. scandens exhibited stronger fumigant toxicity against the maize weevils compared with the essential oils of Artemisia lavandulaefolia $\left(\mathrm{LC}_{50}=11.2 \mathrm{mg} / \mathrm{L}\right)$, A. sieversiana $\left(\mathrm{LC}_{50}=\right.$ $15.0 \mathrm{mg} / \mathrm{L})$ [18], A. vestita $\left(\mathrm{LC}_{50}=13.42\right.$ $\mathrm{mg} / \mathrm{L})$ [20], and Illicium simonsii $\left(\mathrm{LC}_{50}=14.95\right.$ $\mathrm{mg} / \mathrm{L})$ [21]. These findings, considered together, suggest that the essential oil of $P$. scandens has a potential to be developed as a natural fumigant for the control of stored product insects. However, with regard to the 
practical application of the essential oil as a novel fumigant, further studies on the safety of the essential oil in humans as well as formulation development studies would be necessary.

The isolation and identification of the bioactive compounds in the essential oil of $P$. scandens aerial parts are of utmost importance if its potential for controlling stored-product pests is to be realized. Moreover, further studies on plant cultivation and essential oil standardization and production needs to be conducted since the chemical composition of the essential oil varies with the geographical location of plant cultivation.

\section{CONCLUSION}

The essential oil of the aerial parts of $P$. scandens demonstrated activity against maize weevil. However, further studies on the safety of the oil in humans as well as development studies are required to optimize the efficacy and stability of this extract, and to reduce cost. Moreover, further studies on plant cultivation and essential oil standardization are needed due to the wide variations in the chemical composition of the essential oil derived from this plant.

\section{ACKNOWLEDGEMENT}

This work was funded by the Hi-Tech Research and Development of China 2011AA10A202 and National New-Drug Innovation Project 2009ZX09501-014. The authors thank Dr. QR Liu from the College of Life Sciences, Beijing Normal University, Beijing 100875, for the identification of the investigated plant.

\section{REFERENCES}

1. Isman MB. Botanical insecticides, deterrents, and repellents in modern agriculture and an increasingly regulated world. Ann. Rev. Entomol. 2006; 51: 45-66.
2. Committee of Flora of China. Flora of China. Science Press, Beijing, China, Vol. 71, no. 2, 118-119, 1999.

3. Feng T, Li J, Yang Y, Zhou G. Paederia Linn., A newly recorded genus in Rubiaceae in Hebei Province. Hebei J. Forest. Orchard Res. 2002; 17: 228-229 (in Chinese with English abstract).

4. Jiangsu New Medical College. Dictionary of Chinese Herbal Medicine. Shanghai Science \& Technology Press, Shanghai, China, 1977; pp 1214-1215.

5. Ishikura N, Yang Z, Yoshitama K, Kurosawa K. Flavonol glycosides from Paederia scandens var. mairei. Z. Naturforsch. 1990; 45C: 1081 1084.

6. Otsuka $H$. Two new iridoid glucosides from Paederia scandens (Lour.) Merr. var. mairei (Leveille) Hara. Nat. Med. 2002; 56: 59-62.

7. Quang DN, Hashimoto T, Tanaka M, Dung NX, Asakawa $X$. Iridoid glucosides from roots of Vietnamese Paederia scandens. Phytochemistry 2002; 60: 505-514.

8. Kim YL, Chin YW, Kim J, Park JH. Two new acylated iridoid glucosides from the aerial parts of Paederia scandens. Chem. Pharm. Bull. 2004; 52: 1356-1357.

9. Zou X, Peng S, Liu X, Bai B, Ding L. Sulfur-containing iridoid glucosides from Paederia scandens. Fitoterapia 2006; 77: 374-377.

10. Dang, NQ. Anthraquinones from the roots of Paederia scandens. Tap Chi Hoa Hoc 2009; 47: 95-98.

11. Ma YM, Mao Y, Fu JX. Chemical composition of the volatile oil from Paederia scandens. Acta Bot. Boreal. Occident. Sin. 2000; 20: 145-148.

12. Yu AN, Gong FJ, Liu DS. Studies on the chemical constituents of the essential oil from fresh Paederia scandens (Lour.) Merr. J. Hubei Inst. Nation. 2003; 21: 41-43.

13. Liu X, Zhang C, Tian D, Tan Z, Liu Y. Chemical components for volatile oil from Se-enriched Paederia scandens. Food Sci. 2007; 28: 468470.

14. Zhou Q, Liang G, Zeng L. Study on antifeedant effect of plant extracts on Myzus persicae (Sulzer) and Lipaphis erysimi (Kaltenbach). Nat. Prod. Res. Dev. 2004; 16: 521-524.

15. Adams RP. Identification of Essential Oil Components by Gas Chromatograph /Mass Spectrometry. $4^{\text {th }}$ ed. Allured Publishing Corpoartion, Carol Stream, USA, 2007.

16. Sakuma M. Probit analysis of preference data. Appl. Entomol. Zool. 1998; 33: 339-347.

17. Finney DJ. Probit analysis. edn 3, Cambridge University, London. 1971.

18. Liu ZL, Liu QR, Chu SS, Jiang GH. Insecticidal activity and chemical composition of the essential oils of Artemisia lavandulaefolia and Artemisia sieversiana from China. Chem. Biodiv, 2010; 7: 2040-2045.

19. Liu ZL, Ho SH. Bioactivity of the essential oil extracted from Evodia rutaecarpa Hook $f$. et Thomas against the grain storage insects, 
Yang et al

Sitophilus zeamais Motsch. and Tribolium castaneum (Herbst). J. Stored Prod. Res. 1999; 35: 317-328.

20. Chu SS, Liu QR, Liu ZL. Insecticidal activity and chemical composition of the essential oil of Artemisia vestita from China against Sitophilus zeamais. Biochem. Syst. Ecol. 2010; 38: 489492.

21. Chu SS,Liu SL, Jiang GH, Liu ZL. Composition and toxicity of essential oil of Illicium simonsii Maxim (Illiciaceae) fruit against the maize weevils. Rec. Nat. Prod. 2010; 4: 205-210. 